\title{
PROCESSO DE IMPLEMENTAÇÃO DA CERTIFICAÇÃO FLORESTAL NAS EMPRESAS MOVELEIRAS NACIONAIS ${ }^{1}$
}

\author{
Laércio Antônio Gonçalves Jacovine ${ }^{2}$, Ricardo Ribeiro Alves ${ }^{3}$, Sebastião Renato Valverde ${ }^{3}$, Márcio Lopes \\ da Silva ${ }^{2}$, Áurea Maria Brandi Nardelli ${ }^{4}$ e Amaury Paulo de Souza ${ }^{2}$
}

\begin{abstract}
RESUMO - O presente estudo foi desenvolvido com o objetivo de avaliar o processo de implementação da certificação florestal nas empresas moveleiras nacionais. Para a realização deste estudo, utilizaram-se dados secundários, obtidos do website do Conselho de Manejo Florestal (FSC) do Brasil e dados primários, obtidos de questionários aplicado às empresas moveleiras que possuíam produtos certificados. Verificou-se que o tempo gasto no processo, na maioria dos casos, foi de menos de um ano, e os custos principais estiveram relacionados à preparação da empresa para a auditoria de certificação. Além disso, a maioria das empresas afirmou utilizar a logomarca FSC nos seus produtos certificados e não possuíam experiência com outros tipos de certificação (série ISO, por exemplo). Pelos resultados, pode-se concluir que o período de tempo gasto na implementação da certificação é considerado breve, além de os custos serem acessíveis para as empresas, no geral. Concluise, também, que possuir outro tipo de certificação não é fator determinante para que uma empresa da indústria moveleira busque a certificação de cadeia de custódia de seus produtos.
\end{abstract}

Palavras-chave: Certificação florestal, cadeia de custódia e indústria moveleira.

\section{PROCESS OF IMPLEMENTATION OF FOREST CERTIFICATION IN NATIONAL FURNITURE COMPANIES}

\begin{abstract}
The objective of the present study was to evaluate the process of implementation of forest certification in Brazilian furniture companies. Secondary data from the Forest Management Council website (FSC Brazil) and primary data from questionnaires applied to furniture companies producing certified products were used. It was verified that the time spent on the process, in most cases, was less than one year, and the main costs were related with preparing the company for the certification audit. In addition, most companies declared that they use the FSC label in their products and have no experience with other types of certification (ISO series, for example). The results led to the conclusiom that the time spent in the implementation of the certification is considered short and the costs reasonable. The study also concludes that another type of certification is not a determinant factor for a furniture industry to apply for the chain-of-custody certification of its products.
\end{abstract}

Keywords: Forest certification, chain-of-custody and furniture industry.

\footnotetext{
${ }^{1}$ Recebido em 12.09.05 e aceito para publicação em 13.09.2006.

${ }^{2}$ Departamento de Engenharia Florestal da Universidade Federal de Viçosa. E-mail: <jacovine@ufv.br>.

${ }^{3}$ Programa de Pós-Graduação em Ciência Florestal da UFV. E-mail: <ricardo@ vicosa.ufv.br>.

${ }^{4}$ Coordenadora do Programa de Certificação Florestal SGS QUALIFOR no Brasil.
} 


\section{INTRODUÇÃO}

Desde a Conferência Mundial sobre Meio Ambiente (Rio-92) tem surgido uma pressão maior da mídia, da comunidade internacional e das organizações nãogovernamentais (ONGs) no sentido de se buscar uma exploração mais equilibrada dos recursos ambientais. Nesse contexto, afirmaram Coutinho e Soares (2002), as empresas sentem a pressão para adotar uma postura socialmente responsável na condução dos seus negócios. Com relação ao meio ambiente, Nardelli e Griffith (2003a) destacaram que essa postura deve ser precedida, também, por uma mudança de valores empresariais, que irão guiar as futuras estratégias.

A certificação florestal surge como um mecanismo a ser adotado pelas empresas, promovendo a utilização ambientalmente correta e socialmente benéfica dos recursos florestais. Aliada a essas questões, a viabilidade econômica é um ponto-chave para o uso sustentável das florestas tropicais, com vista à industrialização e comercialização dos produtos madeireiros (SILVA, 2003).

Segundo Nardelli (2001), a certificação surgiu no início da década de 1990, como uma alternativa para as campanhas que incentivavam o boicote aos produtos oriundos de florestas tropicais. No lugar de prejudicar toda uma classe de produtos, foram propostos o reconhecimento e consumo de produtos florestais produzidos sob um manejo adequado. Dessa forma, com o objetivo de incentivar o manejo correto das florestas e credenciar as organizações certificadoras, foi criado, em 1993, o Forest Stewardship Council (FSC) ou Conselho de Manejo Florestal (SUITER FILHO, 2000).

Existem duas modalidades de certificação implementadas pelos órgãos credenciados pelo FSC: a) Certificação do Manejo Florestal, quando são certificadas as operações de manejo florestal que atendem aos Princípios e Critérios do FSC (IMAFLORA, 2002); b) Certificação de Cadeia de Custódia $(\mathrm{CoC})$, quando são certificados os produtos florestais através do uso do "selo verde" nesses produtos, com a inspeção de toda a cadeia produtiva, tendo-se a garantia de que toda a matéria-prima utilizada teve sua origem em florestas certificadas (NARDELLI e TOMÉ, 2002). Esse fato é importante porque, muitas vezes, o produto florestal, originado numa unidade de manejo certificada, é transportado e processado por diferentes organizações até chegar ao consumidor final.

R. Árvore, Viçosa-MG, v.30, n.6, p.961-968, 2006
Sobre o mercado desses produtos certificados, Garlipp (2001) afirmou que o processo de certificação é um grande desafio imposto pelos países consumidores, servindo, às vezes, como barreira não-tarifária, que traz implicações e restrições ao comércio de produtos florestais sem essa titulação.

A indústria moveleira é um dos setores produtivos que têm adotado a certificação florestal nos últimos anos, mesmo que timidamente, conforme estudo de Alves (2005). De acordo com Biazin e Godoy (1999), a indústria moveleira brasileira é composta, em sua maioria, por micro e pequenas empresas e apenas cerca de 500 empresas podem ser enquadradas como médias e grandes. Segundo Valença et al. (2002), vários fatores contribuíram para o seu desenvolvimento, a partir de 1990, como a abertura da economia e a ampliação do mercado interno, além do baixo custo da madeira reflorestada.

Assim, torna-se necessário analisar o processo de certificação florestal na indústria moveleira nacional, de forma a subsidiar as empresas que pretendam engajarse nesse novo processo.

O presente estudo teve como objetivo geral avaliar o processo de implementação da certificação florestal nas empresas moveleiras do Brasil. Especificamente, buscou-se:

- Identificar a forma de operação (exclusiva ou não exclusiva), o profissional envolvido na certificação e o tempo médio gasto nesse processo.

- Avaliar os custos diretos e indiretos envolvidos no processo.

- Verificar o atendimento aos padrões requeridos pela certificação.

- Analisar a utilização da logomarca FSC nos produtos certificados.

- Avaliar o grau de conhecimento dessas empresas em relação ao outro sistema de certificação florestal (CERFLOR) e o uso de outros tipos de certificação além da florestal.

- Determinar o grau de satisfação nas empresas que adotaram a certificação florestal.

\section{MATERIAL E MÉTODOS}

O trabalho foi realizado no Departamento de Engenharia Florestal da Universidade Federal de Viçosa 
(UFV), no primeiro trimestre de 2005. Na época, existiam, no Brasil, apenas dois sistemas de certificação: Conselho de Manejo Florestal (Forest Stewardship Council-FSC), de iniciativa internacional, e Sistema Brasileiro de Certificação Florestal (CERFLOR), de iniciativa nacional. Este último reúne a Associação Brasileira de Normas Técnicas (ABNT), Instituto Nacional de Metrologia (INMETRO) e Sociedade Brasileira de Silvicultura (SBS). Tanto o FSC quanto o CERFLOR já estavam aptos a emitir certificação pelo manejo florestal e pela cadeia de custódia. $\mathrm{Na}$ época, apenas o FSC possuía empresas com produtos certificados. Assim, para delimitar as empresas moveleiras nacionais, com certificado de cadeia de custódia, buscaram-se apenas os dados do FSC.

Em dezembro de 2004, existiam 169 empresas com produtos certificados em cadeia de custódia. Para chegar aos números da indústria moveleira, delimitaram-se as empresas que apresentassem "móveis" como produto certificado (escopo da certificação). Obteve-se um total de 28 empresas, representando $16,6 \%$ do total de empresas certificadas no Brasil.

Para a obtenção dos dados desta pesquisa, optouse pela aplicação de um questionário segundo critérios preestabelecidos por auditores e especialistas na área. As respostas foram obtidas através do envio dos questionários por correios e eletronicamente, bem como por contato telefônico.

Das 28 empresas listadas, 10 foram excluídas da avaliação da pesquisa pelos seguintes motivos:

- Duas empresas não possuíam mais a certificação florestal e, portanto, não atendiam aos critérios adotados pela pesquisa.

- Uma empresa atuava exclusivamente como prestadora de serviços na área de "design" e não no processo produtivo.

- Sete empresas não se manifestaram ou apresentaram qualquer resposta ou forma de contato, não havendo garantia de sua existência.

Das 18 empresas aptas a participar da pesquisa, nove responderam ao questionário, correspondendo a 50\% do total. Este número é considerado aceitável, embora os resultados apresentados não possam ser extrapolados para o segmento como um todo.
Através dos dados disponíveis no website do FSC Brasil, obteve-se a informação referente à localização das empresas moveleiras certificadas no Brasil e à evolução da sua certificação florestal; os dados foram agrupados por estado e por ano de certificação. Com relação aos dados referentes às respostas do questionário, utilizou-se a estatística descritiva; e os dados foram organizados e sistematizados por meio de tabulação, sendo empregada uma planilha eletrônica.

\section{RESULTADOS E DISCUSSÃO}

Na certificação da cadeia de custódia, a empresa opta pela utilização única de matéria-prima certificada; este tipo é denominado certificação exclusiva; a empresa poderá utilizar matéria-prima certificada e não-certificada, desde que respeite as porcentagens definidas pelo FSC; neste caso, a certificação é do tipo não-exclusiva. Procurou-se, então, verificar qual a opção adotada pelas empresas moveleiras certificadas. Todas as empresas que responderam à pesquisa informaram que operavam de forma não-exclusiva, ou seja, suas operações florestais utilizam matéria-prima florestal certificada e nãocertificada, obedecendo às porcentagens preestabelecidas pelo FSC.

Com relação ao tipo de profissional envolvido no processo de certificação dessas empresas, houve variabilidade muito grande nas respostas. Diretores, sócios, técnicos florestais, gerentes técnicos, gerentes de recursos humanos, coordenadores de qualidade, gerentes de produção e até presidente foram os cargos citados. Esses profissionais foram responsáveis pela condução e acompanhamento de todas as etapas da certificação nas empresas, desde o contato inicial até a sua obtenção.

O tempo médio gasto no processo foi de até seis meses, desde o primeiro contato até a obtenção da certificação, na maioria das empresas (Figura 1).

As empresas que gastaram menos de um ano para concluir o seu processo de certificação representam $89 \%$ do total. Pode-se deduzir, então, que o tempo médio gasto na certificação de cadeia de custódia nas empresas da indústria moveleira nacional pode ser considerado rápido.

R. Árvore, Viçosa-MG, v.30, n.6, p.961-968, 2006 

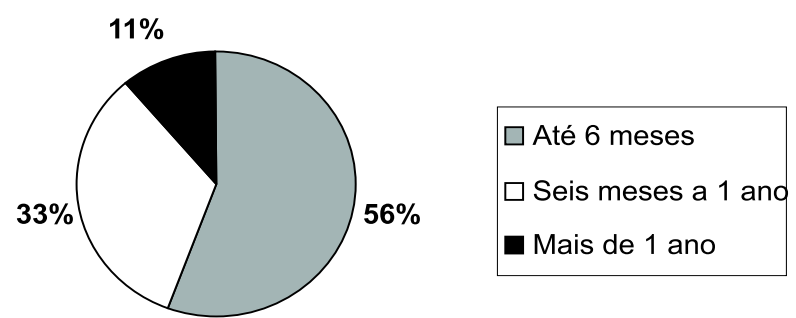

Figura 1 - Tempo médio gasto no processo de implementação, desde o primeiro contato até a obtenção da certificação, nas empresas pesquisadas.

Figure 1-Average time required to complete the implementation process, from the first contact to certification attainment by the studied companies.

Se se comparar o tempo gasto na obtenção de uma certificação de cadeia de custódia, em relação ao tempo gasto com a obtenção de uma certificação do manejo florestal, que envolve mais variáveis, num processo de auditoria, pode-se considerar que a primeira é muito mais rápida. Na cadeia de custódia, o elemento essencial a ser cumprido é a comprovação da rastreabilidade da matéria-prima certificada. No geral, as empresas, com certo grau de organização e controle de processos operacionais, podem obter sua certificação de cadeia de custódia com pouco tempo. Esse tempo relativamente curto pode constituir-se numa motivação a mais para as empresas. O retorno do investimento ocorre mais rápido, e as empresas podem auferir os benefícios advindos da certificação.

\subsection{Custos do processo de obtenção da certificação}

Entrar num processo de certificação florestal implica custos diretos e indiretos. O Imaflora (2002) definiu custos indiretos como aqueles geralmente associados às adaptações no sistema para que uma operação possa atingir e manter a certificação, cumprindo as précondições e condições associadas ao processo. Os custos diretos são definidos como aqueles decorrentes do processo de sua avaliação e monitoramento. $\mathrm{Na}$ maioria das empresas pesquisadas, o custo mais relevante esteve relacionado à preparação da empresa para a obtenção da certificação. Em 78\% dessas empresas, o custo médio indireto foi de até $\mathrm{R} \$ 20.000,00$ (vinte mil reais) (Figura 2).

Esse custo indireto mais acentuado pode ser explicado pelo fato de que muitas empresas têm que estabelecer um processo de controle que garanta a rastreabilidade de sua matéria-prima certificada. Além disso, muitas vezes precisam efetuar um treinamento dos seus funcionários para que estes manipulem o material certificado e o não-certificado, ao longo do processo produtivo e que possam garantir a porcentagem mínima estabelecida pelo FSC ao final.

De acordo com a resposta dada pelas empresas pesquisadas, com relação aos custos diretos (auditoria e manutenção do certificado), pode-se dizer que esses são considerados acessíveis a boa parte das empresas da indústria moveleira.

Os custos referentes à contratação da auditoria para a certificação, na maioria das empresas (78\%), foram de até $\mathrm{R} \$ 10.000,00$ (dez mil reais) (Figura 3). Uma das razões de esse custo não ser tão elevado é a necessidade, em geral, de apenas um auditor, ao longo de um dia, para avaliar a rastreabilidade da matériaprima ao longo do processo; no caso da certificação do manejo florestal, existe um número muito maior de variáveis, o que aumenta o número de dias e auditores necessários para concluir uma auditoria, tornando o processo mais caro.

É importante destacar que esse custo ocorre somente uma vez, ou seja, na ocasião em que a empresa passa pelo processo de auditoria, visando à obtenção da certificação de cadeia de custódia.

Os custos de manutenção do certificado, incluindo o monitoramento e a taxa anual de certificação, também podem ser considerados acessíveis à maioria das empresas da indústria moveleira.

Os resultados apresentados indicam que a maioria das empresas (88\%) tem custos anuais para a manutenção do certificado de até $\mathrm{R} \$ 10.000,00$ (dez mil reais) (Figura 4).

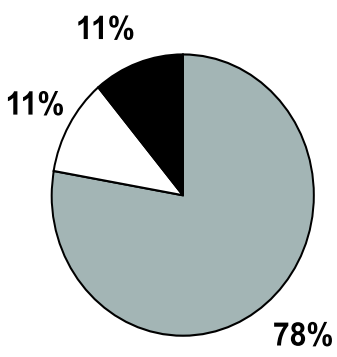

$\square$ Até $R \$ 20.000$
$\square$ De $R \$ 20.000$ até $R \$ 50.000$
Acima de $R \$ 100.000$

Figura 2 - Custos de preparação para a obtenção da certificação florestal (custos indiretos), nas empresas pesquisadas.

Figure 2-Preparation costs for attainment of forest certification (indirect costs), for the studied companies. 


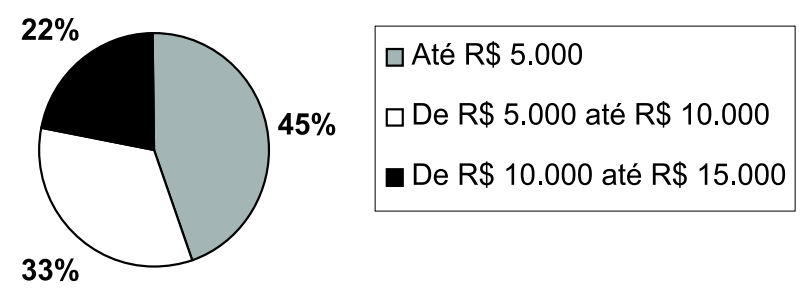

Figura 3 - Custos de contratação da auditoria de certificação, nas empresas pesquisadas.

Figure 3-Contractcostsforcertification auditforthe studied companies.

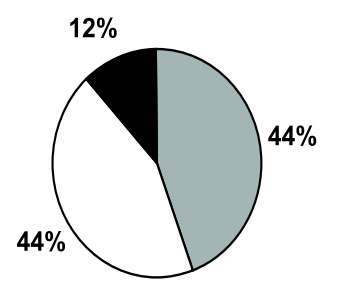

$$
\begin{aligned}
& \square \text { Até } R \$ 5.000 \\
& \square \text { De } R \$ 5.000 \text { até } R \$ 10.000 \\
& \square \text { De } R \$ 10.000 \text { até } R \$ 15.000
\end{aligned}
$$

Figura 4-Custos estimados para a manutenção do certificado. Figure 4-Estimated costs for certificate maintenance.

Quanto aos custos diretos, segundo o Imaflora (2002), são realizados monitoramentos anuais para verificar a manutenção do sistema de cadeia de custódia, que são pagos pela operação. Existem, também, visitas não programadas, que, em geral, não acarretam custos à operação, a não ser que sejam identificadas falhas no sistema e estas gerem ações corretivas.

Os custos podem ser considerados acessíveis às empresas, principalmente pelo fato de serem pagos apenas uma vez por ano; se for diluído, mensalmente, o custo para a empresa será inferior a $\mathrm{R} \$ 1.000,00$ (mil reais). A certificação florestal na indústria moveleira tem atraído, sobretudo, empresas ligadas à exportação (ALVES, 2005), que geralmente possuem capital para investimento; pode-se inferir que tais custos não seriam impedimento às empresas para obter a certificação.

\subsection{A utilização da logomarca FSC nos produtos finais}

A utilização do rótulo FSC nos produtos finais é uma opção da empresa com operação certificada em cadeia de custódia. Dessa forma, verificaram-se os motivos de as empresas usar ou não o rótulo. De acordo com os resultados, $67 \%$ delas declararam fazer uso da logomarca FSC em seus produtos finais.

Segundo as empresas, várias foram as razões que as levaram a empregar a logomarca:

a) A exigência dos clientes, ou seja, a existência de demanda no mercado, citada por $60 \%$ das empresas.
Da mesma forma que a busca por uma certificação está relacionada com as exigências do mercado, a opção de se utilizar o selo no produto (que representa custos adicionais de confecção) também está relacionado com a exigência de seus clientes.

b) Melhoria na imagem institucional, preocupação com o meio ambiente e contribuição na conservação das florestas nativas, diferencial competitivo e argumento na hora das vendas, citados por um número menor de empresas.

Dentre as empresas que não utilizam a logomarca FSC nos seus produtos finais, o principal motivo é que seu cliente ainda não a exige. Para os consumidores, apenas o fato de essa empresa estar certificada já é suficiente, não sendo necessário estampar o selo no produto.

Para o FSC (2005), o uso do rótulo orienta o consumidor na hora da compra, facilitando sua compreensão com relação à origem da matéria-prima. Esse consumidor entende que a madeira (ou outro insumo florestal) utilizada num produto é oriunda de uma floresta manejada, de forma ambientalmente adequada, socialmente benéfica e economicamente viável e que cumpriu todas as leis vigentes. Dessa forma, o consumidor consciente opta por um produto que não degrada as florestas e ainda contribui para o desenvolvimento social e econômico. Além disso, o rótulo também visa orientar o comprador atacadista ou varejista a escolher um produto diferenciado e com valor agregado, capaz de conquistar um público mais exigente e, assim, abrir novos mercados.

\section{3. $O$ atendimento aos padrões exigidos para a certificação}

O processo para a obtenção da certificação de cadeia de custódia exige o cumprimento de alguns padrões. Para verificar o cumprimento desses padrões nas empresas moveleiras certificadas, avaliou-se o grau de facilidade, importância e satisfação no atendimento aos requisitos a serem cumpridos para a certificação, cujos resultados estão apresentados no Quadro 1.

Pelos resultados desse quadro, constatou-se que as empresas tiveram um grau de facilidade médio no atendimento aos padrões exigidos para a certificação, pois se encontram com notas próximas a 5 . As empresas também, em média, julgaram importantes os padrões da certificação de cadeia de custódia e apresentavam um grau de satisfação elevado no cumprimento dessas obrigações.

R. Árvore, Viçosa-MG, v.30, n.6, p.961-968, 2006 
Quadro 1 - Grau de facilidade, importância e satisfação no atendimento aos padrões da certificação de cadeia de custódia, segundo as empresas pesquisadas

Table 1 - Degree of easiness, importance and satisfaction in complying with the standards of chain-of-custody certification for the studied companies

\begin{tabular}{|c|c|c|c|}
\hline $\begin{array}{l}\text { Requisitos a serem Cumpridos } \\
\text { para a Certificação }\end{array}$ & $\begin{array}{c}\text { Grau de Facilidade } \\
\text { no Atendimento } \\
(1 \text { A } 10) *\end{array}$ & $\begin{array}{c}\text { Grau de } \\
\text { Importância } \\
\left(\begin{array}{l}1 \\
\text { A } 10)^{*}\end{array}\right.\end{array}$ & $\begin{array}{c}\text { Grau de Satisfação } \\
\text { da Empresa após a } \\
\text { Implantação }\left(\begin{array}{lll}1 & \text { A } 10)^{*} \\
\end{array}\right.\end{array}$ \\
\hline $\left.1^{\circ}\right)$ Sistema de controle documentado & 5,12 & 9,11 & 8,00 \\
\hline $\left.2^{\circ}\right)$ Confirmação de entradas & 6,34 & 8,77 & 8,88 \\
\hline $\begin{array}{l}3^{\circ} \text { ) Separação e/ou demarcação de } \\
\text { entradas certificadas e não-certificadas }\end{array}$ & 5,12 & 8,88 & 7,13 \\
\hline $\left.4^{\circ}\right)$ Rotulagem segura do produto & 5,23 & 9,22 & 8,75 \\
\hline $5^{\circ}$ ) Identificação da produção certificada & 5,12 & 8,77 & 8,13 \\
\hline $\left.6^{\circ}\right)$ Manutenção de registros & 5,12 & 9,00 & 8,25 \\
\hline $\left.7^{\circ}\right)$ Capacitação de seus funcionários & 4,34 & 9,44 & 7,75 \\
\hline
\end{tabular}

Fonte: dados do autor.

* Foi utilizada a seguinte escala: 1 quando o grau FOR BAIXO, e assim sucessivamente até 10 quando FOR ALTO.

* The following scale was used: 1 for LOW degree successively up to 10 for HIGH degree.

Notou-se que as empresas tiveram grau de dificuldade maior na capacitação de seus funcionários para lidar com os padrões da cadeia de custódia. Geralmente, os funcionários da indústria moveleira, que atuam na produção, não possuem grau de instrução elevado, o que dificulta a sua capacitação. Em contrapartida, as empresas consideravam de extrema importância a capacitação dos funcionários, embora, em média, não estivessem plenamente satisfeitas com esse requisito.

Outro requisito considerado de grande importância pelas empresas é a rotulagem segura do produto certificado. Uma das razões para que isso ocorra pode ser a exigência do FSC de que apenas os produtos que cumprem as porcentagens preestabelecidas estejam rotulados; nesse caso, a empresa deve dar essa garantia. Pelos números mostrados, esse é um dos padrões que está sendo mais bem atendido pelas empresas.

O padrão com o menor grau de satisfação relatado pelas empresas é o que trata da separação e, ou, demarcação de entradas certificadas e não-certificadas. Certamente, esse menor grau de satisfação está relacionado à dificuldade de sua operacionalização, pois deve haver um controle que evite a mistura de material certificado com material não-certificado. Essa dificuldade no controle pode ser provocada, por exemplo, pela alteração de layout do processo fabril ou pela disposição dos produtos na estocagem.

\subsection{Grau de conhecimento da certificação florestal CERFLOR}

O CERFLOR é um programa de certificação florestal com princípios e critérios como o FSC, de iniciativa nacional. No presente trabalho, procurou-se abordar qual o grau de conhecimento que as empresas certificadas tinham do CERFLOR e qual a possibilidade de virem a adotar, também, esse sistema. Pelos resultados, a maioria das empresas, cerca de $67 \%$, conhece a certificação florestal CERFLOR, porém foram unânimes em afirmar que não estariam dispostas a obter tal certificação. Essa certificação era desconhecida por $33 \%$ das empresas.

Dentre os motivos citados para não se buscar a certificação do CERFLOR, estão:

a) O FSC tem maior credibilidade mundial. Isso se deve, possivelmente, ao maior tempo em que o FSC está presente no mercado e, também, à sua abrangência internacional.

b) O CERFLOR, ainda, possui pequena atuação dentro da área plantada/reflorestada nacional. E como certificou sua primeira área de manejo florestal há menos de dois anos, ainda não tem área suficiente para abastecer, por exemplo, uma indústria de MDF, que é uma fornecedora de matéria-prima para as empresas moveleiras.

c) O fato de possuir o selo FSC não torna necessário ter a certificação do CERFLOR para essas empresas. Como são exportadoras, elas entendem que o selo FSC já atende plenamente aos seus interesses, pois possui abrangência internacional, não sendo necessário ter outro tipo de certificação florestal.

Pelos resultados, notou-se uma clara preferência das empresas pelo selo FSC, bem como certa resistência para buscar o CERFLOR. Para obter maior reconhecimento no mercado, o CERFLOR precisaria aumentar sua área 
florestal certificada e estabelecer acordos de reconhecimento mútuo com outros sistemas nacionais de certificação, como o que está em processo, com o sistema europeu The PEFC Council (Programme for the Endorsement of Forest Certification Schemes).

\subsection{Experiência com outros tipos de certificações}

Um dos objetivos desta pesquisa foi avaliar se a certificação florestal possuía alguma interdependência com outros tipos de certificação, a exemplo, da gestão da qualidade (ISO 9001) ou gestão do meio ambiente (ISO 14001). Pressupunha-se que somente as empresas com experiência prévia nessas certificações da série International Organization for Standardization (ISO) poderiam estar em condições para requerer uma certificação florestal, pois denotariam certo grau de organização interna.

De acordo com os resultados, a maioria das empresas não possuía experiência com outros tipos de certificação antes da florestal. Apenas $11 \%$ delas mencionaram dispor de certificação de gestão de qualidade, a ISO 9001 .

Pode-se inferir, então, que possuir outros tipos de certificação, como a de gestão de qualidade ou de gestão do meio ambiente, não é determinante para que as empresas moveleiras busquem a certificação florestal. Empresas que já têm ISO 9001 ou ISO 14001, no entanto, já teriam experiência em cumprir condicionantes e denotariam certo grau de organização que poderia facilitar uma futura implantação da certificação de cadeia de custódia em seus produtos.

\subsection{Grau de satisfação atual das empresas com relação à certificação florestal}

Uma vez que a maioria das empresas possui a certificação de cadeia de custódia há mais de um ano, procurou-se saber o seu grau de satisfação. Perguntouse se a certificação estava atendendo plenamente às suas expectativas, e pediu que citassem as razões.

Pelos resultados, a maioria das empresas $(89 \%)$ demonstrou estar satisfeita com a certificação florestal implantada. Elas apresentaram as seguintes justificativas: aumento nas vendas, melhoria nos resultados, melhoria em sua imagem, melhoria em seu "marketing" e abertura de novos mercados.

Esses resultados apontaram que a certificação florestal funciona como um importante instrumento de mercado. Sobre essa questão, Nardelli e Griffith (2003b) afirmaram que a principal motivação das empresas em aderir aos padrões de certificação têm sido as oportunidades de negócios. Buscar uma certificação florestal, como relatou uma das empresas, é, também, uma forma, ainda que indireta, de poder contribuir para um sistema socialmente benéfico, ecologicamente correto e economicamente viável.

Dentre as empresas que não se encontram satisfeitas com a certificação de cadeia de custódia (11\%), o principal motivo é quanto ao retorno esperado. Acreditava-se que o retorno fosse maior e, por isso mesmo, essas empresas estão reavaliando sua permanência ou não na certificação.

\section{CONCLUSÕES}

Pelos resultados deste trabalho, pode-se concluir que:

- A existência de outros tipos de certificações pela empresa, como a de gestão de qualidade (ISO 9001) ou gestão de meio ambiente (ISO 14001), não é determinante para que uma empresa, do setor moveleiro, busque a certificação florestal.

- O tempo gasto no processo de certificação dessas empresas, desde o contato inicial até a obtenção do selo, pode ser considerado rápido, já que, na maior parte dos casos, foi inferior a um ano.

- As empresas, no geral, encontram-se satisfeitas com a certificação da cadeia de custódia.

- O número de empresas moveleiras certificadas no Brasil é, ainda, muito reduzido.

- Os custos relacionados à certificação foram considerados acessíveis à maioria das empresas moveleiras, principalmente para as exportadoras.

- As empresas consideraram importante ter uma certificação de alcance internacional e, por isso, manifestaram interesse maior pelo FSC.

\section{REFERÊNCIAS BIBLIOGRÁFICAS}

ALVES, R. R. A certificação florestal na indústria moveleira nacional com ênfase no Pólo de Ubá, MG. 2005, 112 f. Dissertação (Mestrado em Ciência Florestal) Universidade Federal de Viçosa, Viçosa, MG, 2005.

R. Árvore, Viçosa-MG, v.30, n.6, p.961-968, 2006 
BIAZIN, C. C.; GODOY, A. M. G. Gestão ambiental: a rotulagem ambiental nas pequenas empresas do setor moveleiro. Rio de Janeiro: RACE-UFRJ, 1999. 13 p.

COUTINHO, R. B. G.; SOARES, T. D. L. A. M. Gestão estratégica com responsabilidade social: arcabouço analítico para auxiliar sua implementação nas empresas no Brasil. Revista de Administração Contemporânea, v. 6, n. 3, p. 75-96, 2002.

\section{FOREST STEWARDSHIP COUNCIL - FSC.}

Disponível em: <http://www.fsc.org.br>. Acesso em 23 maio 2005

GARLIPP, R. C. Recursos Forestales - Brasil. Santiago, Chile: FAO - Food and Agriculture Organization of the United Nations, 2001.58 p.

INSTITUTO DE MANEJO E CERTIFICAÇÃO FLORESTAL E AGRÍCOLA - IMAFLORA. Manual de certificação de cadeia de custódia no sistema do Forest Stewardship Council - FSC.

Piracicaba: 2002. 50 p.

NARDELLI, A. M. B. Sistemas de certificação e visão de sustentabilidade no setor florestal brasileiro. 2001, $136 \mathrm{f}$. Tese (Doutorado em Ciência Florestal) Universidade Federal de Viçosa, Viçosa, MG, 2001.
NARDELLI, A. M. B.; GRIFFITH, J. J.

Mapeamento conceitual da visão de sustentabilidade de diferentes atores do setor florestal brasileiro. Revista Árvore, v. 27, n. 2, p. 241-256, 2003a.

NARDELLI, A. M. B.; GRIFFITH, J. J. Modelo teórico para compreensão do ambientalismo empresarial do setor florestal brasileiro. Revista Árvore, v. 27, n. 6, p. 855-869, 2003b.

NARDELLI, A. M. B.; TOMÉ, M. V. D. F. Efeito multiplicador dos benefícios da certificação florestal. Revista Floresta, Edição especial, p. 94-98, 2002.

SILVA, Z. A. G. P. G. Análise econômica da concentração no uso de madeira tropical pelo setor de marcenarias de Rio Branco, Estado do Acre, 1996. Revista Scientia Forestalis, n. 64, p. 48-58, 2003.

\section{SUITER FILHO, W. Certificação}

Florestal: ferramenta para múltiplas soluções. Revista Ação Ambiental, v. 3 , n. 13 , p. 16-18, 2000 .

VALENÇA, A. C. V.; PAMPLONA, L. M. P.; SOUTO, S. W. Os novos desafios para a indústria moveleira no Brasil. BNDES Setorial, n. 15, p. 83-96, 2002. 